\title{
Prevalence and Correlates of Prenatal Vitamin A Deficiency in Rural Sidama, Southern Ethiopia
}

\author{
Samson Gebremedhin Gebreselassie', Fikre Enquselassie Gase², Melaku Umeta Deressa ${ }^{3}$ \\ 'School of Public and Environmental Health, Hawassa University, PO Box 12485, Addis Ababa, Ethiopia; \\ ${ }^{2} \mathrm{~S} c h o o l$ of Public Health, ${ }^{3} \mathrm{~S} c h o o l$ of Medicine, Addis Ababa University, Ethiopia
}

\begin{abstract}
A cross-sectional study was conducted to assess the prevalence and correlates of prenatal vitamin A deficiency (VAD) in rural Sidama, Southern Ethiopia. Seven hundred randomly-selected pregnant women took part in the study. Serum retinol concentration was determined using high-performance liquid chromatography. Data were analyzed by logistic and linear regression. Interpretation of data was made using adjusted odds ratio (AOR) and adjusted linear regression coefficient. The prevalence of VAD (serum retinol $<0.7 \mu \mathrm{mol} / \mathrm{L}$ ) was $37.9 \%$. Advanced gestational age and elevated C-reactive protein (CRP $\geq 5 \mathrm{mg} / \mathrm{dL}$ ) were negatively associated with retinol concentration $(\mathrm{p}<0.05)$. The odds of VAD was significantly higher among the women with no education and those devoid of self-income. Women aged 35-49 years had 2.23 (95\% CI 1.31-3.81) times higher odds compared to those aged 15-24 years. The lower the dietary diversity score in the preceding day of the survey, the higher were the odds of VAD. With reference to nulliparas, grand multiparas had 1.92 (95\% CI 1.02-3.64) times increased odds of VAD. VAD and zinc deficiency (serum zinc $<8.6$ $\mu \mathrm{mol} / \mathrm{L}$ during the first trimester, or $<7.6 \mu \mathrm{mol} / \mathrm{L}$ during the second or third trimester) were significantly associated with AOR of 1.80 (95\% CI 1.28-2.53). VAD has major public-health significance in the area. Accordingly, it should be combated through enhancement of diet diversity, birth control, and socioeconomic empowerment of women.
\end{abstract}

Key words: Maternal nutrition; Nutritional surveys; Serum retinol; Vitamin A deficiency; Ethiopia

\section{INTRODUCTION}

Vitamin $\mathrm{A}$ is an essential micronutrient required for the normal functioning of the vision system, immunity, epithelial integrity, cellular differentiation, growth and development, and possibly reproduction $(1,2)$. The World Health Organization (WHO) defines vitamin A deficiency (VAD) as tissue concentrations of vitamin A (VA) low enough to have adverse health consequences, even if there is no evidence of clinical deficiency (3).

VAD remains a serious public-health problem in the developing world (4). Preschool children and pregnant women suffer the most widespread and severe effects of VAD (2). According to WHO, VAD is of moderate to severe public-health importance in

Correspondence and reprint requests:

Dr. Samson Gebremedhin Gebreselassie

School of Public and Environmental Health

Hawassa University

PO Box 12485

Addis Ababa

Ethiopia

Email: samsongmgs@yahoo.com

Fax: +251462208755
122 countries (2). Globally, 190 million preschool children and 19 million pregnant women have low serum retinol concentration (2). In countries at risk of $\mathrm{VAD}, 33.3 \%$ of preschool children and $15.3 \%$ of pregnant women are deficient (2).

Several studies linked prenatal VAD with various adverse pregnancy and birth outcomes, including anaemia $(5,6)$, preterm delivery (6-9), intra-uterine growth retardation $(8,10)$, low birthweight $(5,9,11)$, malformations (12), infection (13), pre-eclampsia/ eclampsia (11,13-15), vertical transmission of HIV (16), poor infant growth $(5,11)$, neonatal and infant mortality $(5,17)$, and maternal mortality $(17,18)$. Nevertheless, the negative effects of prenantal VAD on birth outcomes are still controversial.

Studies conducted over decades consistently indicated the public-health significance of VAD in Ethiopia (19). However, the full extent of the problem in pregnant women is not clearly known as most of the studies were carried on preschool children. Although WHO estimated $13.2 \%$ prevalence of VAD in pregnant women in Ethiopia (2), the available three studies (20-22) conducted in the south- 
ern and north-western part of the country reported higher prevalence figures ranging from 17 to 27\%.

The objectives of the current study are to assess the prevalence and potential risk factors of prenatal VAD in Sidama zone, Southern Ethiopia, where an earlier survey (21) reported seriously high (27\%) prevalence of VAD. The current study explored wide range of potential risk factors, including maternal literacy level, income, age, gestational age, household wealth index, agro-ecological zone, zinc deficiency (ZD), parity, birth interval, history of breastfeeding, level of C-reactive protein (CRP), dietary diversity (DD), type of staple food, distance from the nearby health facility, antenatal care (ANC), and history of nutrition education during pregnancy. A previous study (23) has already presented the prevalence and correlates of ZD among similar group of study subjects.

\section{MATERIALS AND METHODS}

\section{Study design}

This is a community-based, cross-sectional study, with descriptive and analytic designs.

\section{Setting}

The study was conducted in January 2011 in 18 kebeles of Sidama zone, Southern Ethiopia. A kebele is the smallest administrative unit in Ethiopia, comprising approximately 1,000 households. Sidama zone is one of the 15 zones of Southern Nations Nationalities and Peoples Regional State (24). The zone has a population of 2,966,652 and population density of $430 / \mathrm{km}^{2}(24)$. In terms of agroecological zone, approximately 50\%, 30\%, and 20\% of the people dwell in the midlands $(1,750-2,300 \mathrm{~m}$ above sea-level (ASL)), highlands (>2,300 m ASL) and lowlands ( $<1750 \mathrm{~m}$ ASL) respectively (25). Livelihood of about $85 \%$ of the population depends on subsistent farming. Major crops grown in the area are enset (Enset ventricosum), coffee, and maize (25).

\section{Sample-size}

Single proportion sample-size calculation formula was used in determining adequate sample-size for estimating the prevalence of VAD. The sample-size of 666 pregnant women was computed based at $95 \%$ confidence level, 5\% margin of error, design effect of 2, 27\% expected prevalence of VAD (21), and $10 \%$ non-response rate. However, to maximize the sample-size for the analytic component of the study, 750 pregnant women were recruited. The adequacy of the available sample-size for investigating the risk factors of VAD was assessed using the
STATCALC application of Epi Info (version 3.5) at 95\% confidence level, 80\% power, and 1:1 ratio between deficient and non-deficient subjects.

\section{Sampling technique}

Initially, all rural kebeles in the zone (total of 456 kebeles) were listed and stratified into three agroecological zones, namely lowlands ( $<1,750 \mathrm{~m} \mathrm{ASL})$, midlands (1,750-2,300 $\mathrm{m}$ ASL), and highlands (>2300 $\mathrm{m} \mathrm{ASL}$ ). Then the total sample-size (750 pregnant women) was divided into three strata (agro-ecological zones) proportionally to their population-size (20\%, 50\%, and 30\% respectively). Six kebeles from every stratum - a total of 18 kebeleswere selected using simple random-sampling technique. Again, the sample-size allotted for each of the stratum was distributed among the respective six kebeles proportionally to their population-size.

In every selected kebele, house-to-house enumeration was conducted to identify pregnant women. Presumptive symptoms of pregnancy (ammenorrhea and/or increased uterine-size), with subsequent urine test for pregnancy (INSTANT-HCG ®, USA), were used for diagnosis of pregnancy. Eventually, 750 subjects were selected using systematic random-sampling technique.

\section{Data-collection method}

A structured and pretested questionnaire was used for assessing potential correlates of VAD. The section of the questionnaire on socioeconomic information was adopted from standard DHS questionnaire, and the part on DD was taken from Food and Nutrition Technical Assistance (FANTA) indicator guideline (26). Other parts of the tool were developed by the principal investigators. The content validity of the tool was assessed against the conceptual framework of the study by relevant professionals, and the reliability of the tool was evaluated using test-retest method.

Data were collected by three trained clinical nurses in private setting within the compound of the nearby health posts. The questionnaire was administered using local language. The altitudes of the study area (in metre above sea-level) was measured at the centre of the kebeles, using Global Positioning System (GPS) (Magellan®, USA), and the kebeles were classified as highlands, midlands, and lowlands based on the aforementioned cutoff points.

Household dietary diversity score (DDS) quantifies DD, based on a 24-hour recall method. Respondents were asked whether they had taken any food from 
predefined 12 food categories in the previous day of the survey. Accordingly, the DDS was computed out of a score of 12 . According to the recommendation of FAO (27), the DDS was categorized into low (DDS $\leq 3$ ), medium (DDS of 4 or 5), or high (DDS $\geq 6$ ).

Mid-upper arm-circumference (MUAC) of the women was measured to the nearest $0.1 \mathrm{~cm}$, using MUAC tape. The measurement was taken on the middle left arm at relaxed position, without any clothing and with optimal tape tension. Severe acute malnutrition (SAM) was defined as MUAC less than $220 \mathrm{~mm}(28)$.

\section{Blood sample collection, serum extraction, and laboratory analysis}

Venous blood was collected using stainless steel needles and plain tubes (SARSTEDT Monovette ${ }^{\circledR}$, Germany). The blood was clotted for 20 minutes and consecutively centrifuged at $3000 \times \mathrm{g}$ for 10 minutes. Visibly-haemolyzed samples were discarded. Serum was extracted and transferred immediately into screw-top vials. The samples were transported in icebox, protected from direct light, and kept frozen at $-20^{\circ} \mathrm{C}$ until analyzed.

Serum retinol and zinc concentrations were determined at Ethiopian Health and Nutrition Research Institute following standard procedures, using highperformance liquid chromatography (Shimadzu®, Japan) and flame atomic absorption spectrometer (Varian SpectrAA®, Australia) respectively. VAD (serum retinol $<0.7 \mu \mathrm{mol} / \mathrm{L}$ ) and marginal VAD (serum retinol 0.7 to $1.05 \mu \mathrm{mol} / \mathrm{L}$ ) were defined according to the recommendation of WHO (2) whereas ZD (serum zinc $<8.6 \mu \mathrm{mol} / \mathrm{L}$ during the first trimester or $<7.6 \mu \mathrm{mol} / \mathrm{L}$ during the second or third trimester) was defined according to the recommendation of International Zinc Nutrition Consultative Group (29). CRP was determined qualitatively, using Latex test (HumaTex CRP®, Germany). A distinctively visible agglutination was indicative of positive CRP result (CRP $>5 \mathrm{mg} / \mathrm{dL})$.

\section{Data analysis}

Data-entry, screening, and analysis were carried out using SPSS 19.0 for Windows. The distribution of serum retinol level was assessed using Q-Q plot and found to be normal. Descriptive analysis was done using mean, frequency, and percentage. Independent $t$-test and one-way analysis of variance (ANOVA) were used in comparing retinol level across categories of independent variables. The assumptions of ANOVA (normal distribution and homoscedasticity of the dependent variable across the categories of independent variables) were checked to be fulfilled.

Wealth index was computed as a composite indicator of living standard, based on ownership of selected household assets, size of agricultural land, quantity of livestock, materials used for house construction, and ownership of improved water and sanitation facilities. The variables were reduced to a continuous variable, using principal component analysis. Ultimately, the five wealth index categories (poorest, poorer, middle, richer, and richest) were generated by splitting the continuous variable into 5 equal quintiles.

Logistic and linear regression analyses were used in controlling potential confounders. Independent variables significantly $(\mathrm{p}<0.05)$ associated with the dependent variable in simple regression models were exported to multiple regression models for adjustment. In multivariate logistic regression analyses, variables were entered separately into two models-distal and proximate. Factors which can directly affect serum retinol level were considered proximate factors whereas factors which have to function through the proximate factors to affect serum retinol level were considered distal factors. The distal model comprised agro-ecological zone, wealth index, maternal education, and women's participation in income-generating activities (IGAs). The proximate model included maternal age, gestational age, CRP level, DDS, and consumption of foods of animal source in the preceding day of the survey, ZD, distance from the nearby health facility, ANC, history of nutrition education during pregnancy, and SAM status. In the multivariate linear regression model, only the proximate factors were modelled as the $r$-squared value for distal model was extremely low.

The major assumptions of logistic regression analysis (absence of influential cases, multicollinearity and interaction among independent variables) and linear regression analysis (normally-distributed error terms, linear relation between dependent and independent variables, homoscedasticity, and absence of multicollinearity) were checked to be satisfied. The fitness of logistic and linear regression models were assessed using Hosmer-Lemeshow statistic and adjusted $r$-squared values respectively.

\section{Ethical considerations}

The study was conducted in confirmation of the national and international ethical guidelines for biomedical research involving human subjects. Ethical 
clearance was granted by the institutional review board of Addis Ababa University. Informed written consent was taken from the study subjects. Needle safety procedures were in line with international standards. After data collection, the data collectors provided nutrition education to all study participants.

\section{RESULTS}

\section{Background information on study subjects}

Of 750 pregnant women sampled, 700 (93.3\%) were willing to take part in the study. Nearly half of the study participants-357 (51.0\%)—were from the midlands whereas the remaining 187 (26.7\%) and 156 (22.3\%) were from highlands and lowlands respectively.

The mean age ( \pm standard deviation) of the respondents was $28.5 \pm 5.5$ years. About 50 (7.2\%), 347 (49.6\%), and 303 (43.3\%) were in the first, second and third gestational trimester respectively. Nearly two-thirds-462 (66.0\%)—had no education, and $561(80.1 \%)$ were housewives. The vast majority$679(97.0 \%)$ and 596 (85.1\%)—were Sidama in ethnicity and Protestants in religion respectively. The average household-size was $4.3 \pm 1$. . The average size of agricultural land per household was $0.38 \pm 0.19$ hectares.

\section{Prevalence of vitamin A deficiency}

The mean serum retinol level was $0.84 \pm 0.41$ $\mu \mathrm{mol} / \mathrm{L}$ (95\% CI 0.81-0.87). The levels in the first, second and third trimester were $0.97 \pm 0.40$, $0.89 \pm 0.42$ and $0.76 \pm 0.40 \mu \mathrm{mol} / \mathrm{L}$ respectively. The retinol level in the third trimester was significantly lower than the corresponding values for the first and second trimesters $(\mathrm{F}=11.08, \mathrm{p}=0.000)$. Based on the cutoff point recommended by WHO (2), 265 [37.9\% (95\% CI 34.3-41.5)] of the subjects had VAD, and additional 201 [28.7\% (95\% CI 25.332.1)] subjects had marginal VA status (Figure). Pregnant women in the third trimester had 2.59 (95\% CI 1.23-5.48) times increased odds of VAD compared to those in the first trimester.

About 59 (8.4\%) of the blood samples were positive for CRP (CRP $\geq 5 \mathrm{mg} / \mathrm{dL}$ ). The retinol levels for CRP-negative and positive samples were $0.85 \pm 0.42$ and $0.66 \pm 0.34 \mu \mathrm{mol} / \mathrm{L}$ respectively. The difference was significant $(t=3.828, \mathrm{p}=0.000)$. Elevated CRP was associated with $22.5 \%$ reduction in serum retinol concentration. Positive CRP result was significantly associated with VAD with AOR 2.21 (95\% CI 1.22-4.02).

\section{Correlates of vitamin A deficiency}

\section{Sociodemographic factors}

Maternal age was negatively associated with VAD. The retinol concentrations for women aged 15-24, 25-34, and 35-49 years were 0.89 $\pm 0.44,0.85 \pm 0.40$, and $0.71 \pm 0.41 \mu \mathrm{mol} / \mathrm{L}$ respectively. The global difference was significant $(\mathrm{F}=6.890, \mathrm{p}=0.001)$. The

Figure. Prevalence of vitamin A deficiency among pregnant women in rural Sidama, Southern Ethiopia, February 2011

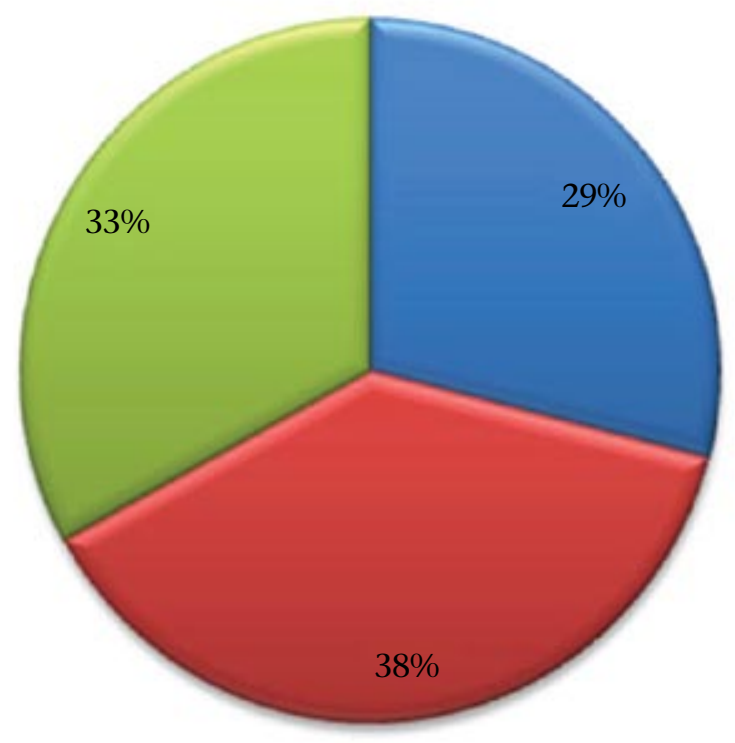

Marginal (0.7-1.05 $\mu \mathrm{mol} / \mathrm{L}$

Deficient $(<0.7 \mu \mathrm{mol} / \mathrm{L}$

Normal (>1.05 $\mu \mathrm{mol} / \mathrm{L}$ 
odds ratio of VAD was 2.23 (95\% CI 1.31-3.81) times higher in the oldest participants compared to the youngest group.

The study witnessed no significant association between household wealth index and maternal VA status. Nevertheless, women's participation in IGAs was positively associated. Retinol level among women who were involved in IGA was significantly higher than their counterparts ( $t=2.557, \mathrm{p}=0.012)$. Likewise, women who were devoid of self-income had 2.18 (95\% CI 1.29-3.69) times higher odds of VAD.

Maternal education showed a positive influence on VA status. The retinol levels among the women who had no education, who completed first to fourth grade and beyond fourth grade were $0.80 \pm 0.43,0.87 \pm 0.38$, and $0.93 \pm 0.38 \mu \mathrm{mol} / \mathrm{L}$ respectively. The global difference across the categories was significant $(\mathrm{F}=19.682, \mathrm{p}=0.000)$. Women without education had 1.73 times (95\% CI 1.022.92) higher odds of VAD compared to women educated beyond the fourth grade.

The odds of VAD were not significantly different across the three agro-ecological zones.

\section{Nutritional factors}

Dietary diversity level was assessed, based on a 24hour recall method. The diet was predominated by roots and tubers, cereals, and legumes. In the reference period, 549 (78.4\%), 369 (52.7\%), and 366 (52.2\%) consumed roots and tubers (mainly enset), cereals (mainly maize), and legumes (mainly broad bean and kidney bean) respectively. Only 199 (28.4\%) and 181 (25.6\%) reported consumption of provitamin A and preformed vitamin A-rich foods respectively.

Based on ANOVA and logistic regression analyses, the level of DD and consumption of foods from animal source in the reference period were positively associated with VA status. Women with low DDS had 1.94 (95\% CI 1.17-3.19) times increased odds of VAD compared to women with high DDS. Those who did not consume foods from animal source in the preceding day had 1.51 times (95\% CI 1.042.13) higher odds than their counterparts.

The retinol level among respondents who considered maize as their staple diet $(0.88 \pm 0.42 \mu \mathrm{mol} / \mathrm{L})$ was significantly higher than those who reported enset $[(0.81 \pm 0.41 \mu \mathrm{mol} / \mathrm{L})(t=2.028, \mathrm{p}=0.043)]$. Nonetheless, the association was not significant in the logistic model. Similarly, VA status was not significantly associated with SAM status (Table 1).
VAD and ZD tend to occur together. A quarter$24.9 \%$ (95\% CI 21.7-28.1)—of the subjects had both of the deficiencies, and about two-thirds65.6\% (95\% CI 59.9-71.4)—of the vitamin A-deficient subjects were zinc-deficient. After controlling for joint nutritional and non-nutritional determinants, VAD and ZD were significantly associated with AOR of 1.80 (95\% CI 1.28-2.53).

\section{Reproductive and healthcare factors}

Parity and VA status were negatively associated. Significant difference in retinol concentrations was witnessed across parity of $0,1-2,3-4$, and 5 or more $(\mathrm{F}=2.886, \mathrm{p}=0.035)$. Compared to nulliparas, grand multiparas had 1.92 times (95\% CI 1.02-3.64) higher odds of VAD.

Among 553 subjects who gave at least one birth in the preceding five years of the survey, the interval between the previous birth and the expected date of birth in the index pregnancy was estimated. The retinol levels in women with short ( $<24$ months) and optimal ( $\geq 24$ months) birth intervals were $0.72 \pm 0.45$ and $0.84 \pm 0.41 \mu \mathrm{mol} / \mathrm{L}$ respectively. The difference was significant $(t=2.032, \mathrm{p}=0.043)$. Women with short birth interval had 2.11 times (95\% CI 1.15-3.86) higher odds of VAD.

The association between duration of breastfeeding and VA status was assessed among 492 women who reported history of breastfeeding in the previous five years of the survey. The retinol concentrations in mothers who breastfed for durations less than 18 months, $18-24$ months and greater than 24 months, were $0.99 \pm 0.42,0.87 \pm 0.42$, and $0.79 \pm 0.40 \mu \mathrm{mol} / \mathrm{L}$ respectively. The global difference was significant ( $\mathrm{F}=6.491, \mathrm{p}=0.002$ ). Post-hoc Tukey test identified that the retinol level among women who breastfed for more than 24 months was significantly lower than those who breastfed for less than 18 months.

Serum retinol level and odds of VAD were compared across various healthcare service-related factors. However, physical distance from the nearby health facility, frequency of ANC, and receiving nutrition education during pregnancy were not associated with VA status (Table 1).

\section{Linear regression modelling}

In the linear regression model, about $26.2 \%$ of the variability in serum retinol level $(\mu \mathrm{mol} / \mathrm{L})$ was explained by 8 independent variables (Table 2). Unit increment in maternal age (in years), parity, and gestational age (in months) were associated with 


\begin{tabular}{|c|c|c|c|c|c|}
\hline Variable & $\begin{array}{c}\text { Serum } \\
\text { retinol } \mu \mathrm{mol} / \mathrm{L} \\
(\text { mean } \pm \mathrm{SD})\end{array}$ & VAD+ & VAD- & $\begin{array}{l}\text { Crude OR } \\
(95 \% \mathrm{CI})\end{array}$ & $\begin{array}{l}\text { Adjusted OR } \\
(95 \% \mathrm{CI}) * *\end{array}$ \\
\hline \multicolumn{6}{|l|}{ Staple diet } \\
\hline Enset-based & $0.81 \pm 0.41$ & 180 & 271 & $1.28(0.93-1.77)$ & - \\
\hline Cereal-based & $0.88 \pm 0.42$ & 85 & 164 & $1^{\mathrm{r}}$ & - \\
\hline \multicolumn{6}{|l|}{$\begin{array}{l}\text { Dietary diversity in the } \\
\text { previous day }\end{array}$} \\
\hline Low $(\mathrm{DDS} \leq 3)$ & $0.75 \pm 0.41$ & 119 & 124 & $2.55(1.63-4.00)^{*}$ & $1.94(1.17-3.19)^{*}$ \\
\hline Optimal (DDS of 4 or 5) & $0.87 \pm 0.41$ & 108 & 210 & $1.37(0.88-2.12)$ & $1.10(0.70-1.72)$ \\
\hline High (DDS $\geq 6$ ) & $0.91 \pm 0.43$ & 38 & 101 & $1^{\mathrm{r}}$ & $1^{\mathrm{r}}$ \\
\hline \multicolumn{6}{|l|}{$\begin{array}{l}\text { Consumed foods from animal } \\
\text { source in the previous day }\end{array}$} \\
\hline No & $0.81 \pm 0.42$ & 216 & 303 & $1.92(1.33-2.78)^{*}$ & $1.51(1.04-2.13)^{*}$ \\
\hline Yes & $0.91 \pm 0.39$ & 49 & 132 & $1^{\mathrm{r}}$ & $1^{\mathrm{r}}$ \\
\hline \multicolumn{6}{|l|}{ Severe acute malnutrition } \\
\hline No (MUAC $\geq 220 \mathrm{~mm}$ ) & $0.87 \pm 0.42$ & 178 & 330 & $1^{\mathrm{r}}$ & $1^{\mathrm{r}}$ \\
\hline Yes (MUAC <220 mm) & $0.75 \pm 0.39$ & 87 & 105 & $1.54(1.10-2.15)^{*}$ & $1.26(0.88-1.81)$ \\
\hline \multicolumn{6}{|l|}{ Zinc deficiency status } \\
\hline Non-deficient & $0.92 \pm 0.41$ & 91 & 238 & $1^{\mathrm{r}}$ & $1^{\mathrm{r}}$ \\
\hline Deficient & $0.76 \pm 0.40$ & 174 & 197 & $2.31(1.68-3.17)^{\star}$ & $1.80(1.28-2.53)^{*}$ \\
\hline \multicolumn{6}{|l|}{ Parity } \\
\hline 0 & $0.89 \pm 0.40$ & 34 & 82 & $1^{\mathrm{r}}$ & $1^{\mathrm{r}}$ \\
\hline $1-2$ & $0.85 \pm 0.41$ & 102 & 174 & $1.41(0.86-2.26)$ & $1.14(0.69-1.87)$ \\
\hline $3-4$ & $0.84 \pm 0.42$ & 91 & 140 & $1.57(0.97-2.53)$ & $1.35(0.81-2.26)$ \\
\hline$\geq 5$ & $0.72 \pm 0.40$ & 38 & 39 & $2.35(1.29-4.28)^{*}$ & $1.92(1.02-3.64)^{*}$ \\
\hline \multicolumn{6}{|l|}{$\begin{array}{l}\text { Walking distance from near- } \\
\text { by health facility }\end{array}$} \\
\hline 0-30 minutes & $0.83 \pm 0.41$ & 229 & 369 & $1^{\mathrm{r}}$ & - \\
\hline Longer than 30 minutes & $0.89 \pm 0.44$ & 36 & 66 & $0.88(0.57-1.36)$ & - \\
\hline \multicolumn{6}{|l|}{ Number of ANC follow-ups } \\
\hline 0 & $0.87 \pm 0.41$ & 121 & 243 & $1^{\mathrm{r}}$ & $1^{\mathrm{r}}$ \\
\hline $1-2$ & $0.80 \pm 0.43$ & 134 & 173 & $1.56(1.14-2.13)^{*}$ & $1.42(0.97-2.02)$ \\
\hline$\geq 3$ & $0.86 \pm 0.41$ & 10 & 19 & $1.06(0.48-2.34)$ & $0.70(0.30-1.64)$ \\
\hline \multicolumn{6}{|l|}{$\begin{array}{l}\text { Received nutrition education } \\
\text { during pregnancy }\end{array}$} \\
\hline Yes & $0.80 \pm 0.41$ & 70 & 105 & $1^{\mathrm{r}}$ & - \\
\hline No & $0.85 \pm 0.42$ & 195 & 330 & $0.89(0.62-1.26)$ & - \\
\hline
\end{tabular}

$0.01,0.04$, and $0.03 \mu \mathrm{mol} / \mathrm{L}$ decline in serum retinol level respectively. On the contrary, a unit increment in DDS and MUAC (in $\mathrm{cm}$ ) was associated with 0.04 and $0.02 \mu \mathrm{mol} / \mathrm{L}$ rise in retinol concentration. Serum zinc and retinol concentrations were positively associated with unstandardized coefficient of 0.03. An adjusted net difference of 0.12 $\mu \mathrm{mol} / \mathrm{L}$ was observed between CRP-positive and negative samples. Similarly, a significant difference of $0.12 \mu \mathrm{mol} / \mathrm{L}$ was witnessed between those who 


\begin{tabular}{|lccc|}
\hline $\begin{array}{c}\text { Table 2. Linear regression output on the predictors of serum retinol concentrations }(\mu \mathrm{mol} / \mathrm{L}) \text { among } \\
\text { pregnant women in rural Sidama, Southern }\end{array}$ \\
\hline Indepiopia February 2011 & $\begin{array}{c}\text { Unstandardized } \\
\text { coefficient }\end{array}$ & $t$-statistic & $\begin{array}{c}\mathrm{p} \\
\text { value }\end{array}$ \\
\hline Constant & 0.481 & & \\
Maternal age (years) & -0.008 & -2.474 & 0.014 \\
Parity (0-9) & -0.036 & -3.343 & 0.001 \\
Gestational age (months) & -0.030 & -3.730 & 0.000 \\
Diet diversity level in the previous day (0-12) & 0.040 & 4.429 & 0.000 \\
Mid-upper arm-circumference (cm) & 0.018 & 2.515 & 0.012 \\
Consumed foods from animal source in the previous & 0.117 & 3.575 & 0.000 \\
day (0=no, 1=yes) & -0.120 & -2.339 & 0.020 \\
CRP (0=Negative, 1=Positive) & 0.034 & 3.545 & 0.000 \\
Serum zinc concentration (in $\mu \mathrm{mol} / \mathrm{L})$ & & \\
\hline
\end{tabular}

consumed foods from animal source in the previous day of the survey and their counterparts.

\section{DISCUSSION}

According to $\mathrm{WHO}$, the public-health significance of VAD is considered to be of severe degree when the prevalence of low serum retinol $(<0.70 \mu \mathrm{mol} / \mathrm{L})$ in pregnant women exceeds $20 \%$ from the reference value (2). Accordingly, with the prevalence of $37.9 \%$, VAD is of severe public-health importance in the area.

As the study is cross-sectional, the reported prevalence is liable to seasonality bias. If the study had been conducted in drought-prone months, like May, June, and July, a higher prevalence of VAD would have been anticipated. On the other hand, the study might have over-estimated the prevalence as women in the first trimester were largely under-represented.

Few studies attempted to determine the prevalence of subclinical VAD among pregnant women in Ethiopia. Gibson et al. reported 27\% prevalence of VAD among 85 pregnant women in three kebeles of Sidama (21). The prevalence is comparable with the current study in the sense that the confidence intervals overlapped. However, the apparent difference in the point estimators might be due to the fact that the earlier study included convenientlyselected women in relatively accessible kebeles.

Two studies conducted among ANC attendants in Gondar Hospital, Northwestern Ethiopia, found $17.2 \%$ (20) and $18.4 \%$ (22) prevalence of subclinical VAD. The current study reported relatively higher prevalence, probably due to the reason that the earlier studies were conducted in an urban setup where prevalence of VAD is expected to be lower.
According to EDHS 2005, the prevalence of maternal night-blindness in rural areas of Ethiopia was two times higher than that in the urban areas (30).

Gestational trimester and VA status were negatively associated, apparently due to the effect of haemodilution. Parallel findings were reported in Zimbabwe (31), India (32), and Turkey (33). In the current study, serum retinol significantly declined by about $22 \%$ from the first $(0.97 \mu \mathrm{mol} / \mathrm{L})$ to the third trimester $(0.76 \mu \mathrm{mol} / \mathrm{L})$. A study in Indonesia also reported a comparable $20 \%$ reduction (34). The finding suggests the need for having trimester-specific cutoff points for defining prenatal VAD.

Elevated CRP was associated with $22.5 \%$ reduction in serum retinol concentration. The finding is consistent with the understanding that inflammation causes reduction in serum retinol as a consequence of the acute-phase response $(1,35)$. A meta-analysis also concluded that elevated CRP protein is associated with $25 \%$ decline in retinol level (36). However, in the current study, the negative association observed between CRP and retinol levels can also be the manifestation of vicious causal relationship between infection and VAD.

Analysis based on the data of the third US National Health and Nutrition Examination Surveys concluded that serum retinol among females remains constant between 20 and 49 years of age (37). However, in the current study, maternal age and VA status were negatively associated. The reason for divergence might be: in the developing world, repeated nutritionally-deleterious lifetime events, like extended breastfeeding and drought, frequently occur and deplete maternal store of retinol across the lifespan. Ethiopian DHS 2005 also found that the prevalence of maternal night-blindness tends 
to increase with age (30). Studies in India (38) and Nepal (39) concluded likewise.

Unlike many previous findings (38-40), household wealth status was not associated with VAD status. The unexpected finding might be explained based on the reason that household wealth status was measured using a relative rather than an absolute index. It means, as the study population had minimal wealth variation, wealth index might have lacked the ability to detect significant association with VAD. Nevertheless, involvement of women in IGAs was found to have beneficial effect, irrespective of household wealth and maternal education status.

History of too close and too many births was associated with higher odds of VAD. This is consistent with the understanding that repeated reproductive cycles deplete maternal store of nutrients (41). Previous studies in the developing world also reported the same. A study in Southern India reported a twofold increased risk of night-blindness among grand multiparas compared to nulliparas women (38). Studies in Cambodia (40) and Nepal (39) found 1.5 and 1.6 times higher risk of night-blindness respectively in women with 3 or more previous births compared to their counterparts.

VAD and ZD were positively associated in our study. Potential nutritional and non-nutritional confounders cannot explain the association as they had been statistically controlled. The association can be secondary to the influence of zinc on the metabolism of vitamin A (42). A study in pregnant rhesus monkeys concluded that, in the zincdeficient groups, zinc affects vitamin A metabolism by altering the formation or release of holo-retinolbinding protein (43). Zinc supplementation trial in pregnant Nepalese women also suggested that zinc potentiates the effect of vitamin A in restoring night-vision among night-blind pregnant women with low initial serum zinc concentrations (44).

Distance from the nearby health facility, prenatal nutrition education/counselling, and frequency of ANC were not associated with vitamin A status. This might be due to the reason that nutritional care is not well-integrated into maternity services. In addition, the provision of nutrition education might not be effective in the absence of concurrent livelihood promotion strategies.

\section{Conclusions}

The study was conducted in socioeconomicallydisadvantaged and food-insecure locality. With a prevalence of $38 \%$, VAD has severe degree of public-health significance in the area. Advanced gestational age was negatively associated with serum retinol level, indicating that there is a need for developing trimester-specific cutoff points for defining prenatal VAD. Elevated CRP, advanced age, inferior maternal socioeconomic status, dependence on poorly-diversified and plant sourcebased diets, zinc deficiency, and history of too close and too many births were pertinent risk factors of VAD. ANC and nutrition education were not potent enough in reducing the burden of VAD. VAD should be combated through improving diet diversity and expansion of family-planning services in the area. Socioeconomic empowerment of women would also have positive contribution. Nutritional care should be integrated into maternity services.

\section{ACKNOWLEDGEMENTS}

Special thanks go to all study subjects who volunteered to participate in the study. The authors acknowledge Addis Ababa University School of Public Health for funding the study and Ethiopian Health and Nutrition Research Institute for conducting the laboratory analyses.

\section{REFERENCES}

1. Gibson RS. Principles of nutritional assessment. 2nd ed. New York, NY: Oxford University Press, 2005. 908 p.

2. World Health Organization. Global prevalence of vitamin A deficiency in populations at risk 1995-2005: WHO global database on vitamin A deficiency. Geneva: World Health Organization, 2009. 55 p.

3. World Health Organization, Food and Agriculture Organization of the United Nations. Vitamin and mineral requirements in human nutrition: vitamin A. 2nd ed. Geneva: World Health Organization, 2004:17-37.

4. West KP, Jr. Extent of vitamin A deficiency among preschool children and women of reproductive age. J Nutr 2002;132(Suppl 9):2857S-66S.

5. Kumwenda N, Miotti PG, Taha TE, Broadhead R, Biggar RJ, Jackson JB et al. Antenatal vitamin A supplementation increases birth weight and decreases anemia among infants born to human immunodeficiency virus-infected women in Malawi. Clin Infect Dis 2002;35:618-24.

6. Radhika MS, Bhaskaram P, Balakrishna N, Ramalakshmi BA, Devi S, Kumar BS. Effects of vitamin A deficiency during pregnancy on maternal and child health. BJOG 2002;109:689-93.

7. Coutsoudis A, Pillay K, Spooner E, Kuhn L, Coovadia HM. Randomized trial testing the effect of vitamin 
A supplementation on pregnancy outcomes and early mother-to-child HIV-1 transmission in Durban, South Africa. South African Vitamin A Study Group. AIDS 1999;13:1517-24.

8. Agarwal K, Dabke AT, Phuljhele NL, Khandwal OP. Factors affecting serum vitamin A levels in matched maternal-cord pairs. Indian J Pediatr 2008;75:443-6.

9. Ghebremeskel K, Burns L, Burden TJ, Harbige L, Costeloe K, Powell JJ et al. Vitamin A and related essential nutrients in cord blood: relationships with anthropometric measurements at birth. Early Hum Dev 1994;39:177-88.

10. Neel NR, Alvarez JO. Chronic fetal malnutrition and vitamin A in cord serum. Eur J Clin Nutr 1990;44:207-12.

11. Jendryczko A, Drozdz M. Plasma retinol, beta-carotene and vitamin $\mathrm{E}$ levels in relation to the future risk of pre-eclampsia. Zentralbl Gynakol 1989;111:1121-3.

12. Huang Y, Zheng S. The effect of vitamin A deficiency during pregnancy on anorectal malformations. J Pediatr Surg 2011;46:1400-5.

13. Christian P, West KP, Jr., Khatry SK, Katz J, Shrestha SR, Pradhan EK et al. Night blindness of pregnancy in rural Nepal--nutritional and health risks. Int J Epidemiol 1998;27:231-7.

14. Zhang C, Williams MA, Sanchez SE, King IB, WareJauregui S, Larrabure G et al. Plasma concentrations of carotenoids, retinol, and tocopherols in preeclamptic and normotensive pregnant women. Am J Epidemiol 2001;153:572-80.

15. Williams MA, Woelk GB, King IB, Jenkins L, Mahomed K. Plasma carotenoids, retinol, tocopherols, and lipoproteins in preeclamptic and normotensive pregnant Zimbabwean women. Am J Hypertens 2003;16:665-72.

16. Semba RD, Miotti PG, Chiphangwi JD, Saah AJ, Canner JK, Dallabetta GA et al. Maternal vitamin A deficiency and mother-to-child transmission of HIV-1. Lancet 1994;343:1593-7.

17. Christian P, West KP, Jr., Khatry SK, Kimbrough-Pradhan E, LeClerq SC, Katz J et al. Night blindness during pregnancy and subsequent mortality among women in Nepal: effects of vitamin A and beta-carotene supplementation. Am J Epidemiol 2000;152:542-7.

18. West KP, Jr., Katz J, Khatry SK, LeClerq SC, Pradhan EK, Shrestha SR et al. Double blind, cluster randomised trial of low dose supplementation with vitamin A or beta carotene on mortality related to pregnancy in Nepal. The NNIPS-2 Study Group. BMJ 1999;318:570-5.

19. Gebremedhin S, Loha E, Abebe Y, Dese G. Assessment of vitamin A supplementation coverage and its association with childhood illness in Boloso Sore Woreda,
Welayta Zone, SNNP Region, Ethiopia. Ethiop J Health Dev 2009;23:223-8.

20. Wondmikun Y. Lipid-soluble antioxidants status and some of its socio-economic determinants among pregnant Ethiopians at the third trimester. Public Health Nutr 2005;8:582-7.

21. Gibson RS, Abebe Y, Stabler S, Allen RH, Westcott JE, Stoecker BJ et al. Zinc, gravida, infection, and iron, but not vitamin B-12 or folate status, predict hemoglobin during pregnancy in Southern Ethiopia. J Nutr 2008;138:581-6.

22. Mulu A, Kassu A, Huruy K, Tegene B, Yitayaw G, Nakamori $\mathrm{M}$ et al. Vitamin A deficiency during pregnancy of HIV infected and non-infected women in tropical settings of Northwest Ethiopia. BMC Public Health 2011;11:569.

23. Gebremedhin S, Enquselassie F, Umeta M. Prevalence of prenatal zinc deficiency and its association with socio-demographic, dietary and health care related factors in rural Sidama, Southern Ethiopia: a crosssectional study. BMC Public Health 2011;11:898.

24. Ethiopia. Population Census Commission. Summary and statistical report of the 2007 population and housing census: population size by age and sex. Addis Ababa: Population Census Commission, Federal Democratic Republic of Ethiopia, 2008. 113 p.

25. Lemessa D. Ethiopia: uncertain food security situation for farmers in Sidama Zone due to lack of access to farm inputs. Addis Ababa: UNDP Emergencies Unit for Ethiopia, 2002. (http://reliefweb.int/report/ ethiopia/ethiopia-uncertain-food-security-situationfarmers-sidama-zone-due-lack-access-farm, accessed on 26 May 2013).

26. Swindale A, Bilinsky P. Household dietary diversity score (HDDS) for measurement of household food access: indicator guide. Version 2. Washington, DC: Food and Nutrition Technical Assistance Project, USAID, 2006. 9 p.

27. Kennedy G. Ballard T, Dop MC. Guidelines for measuring household and individual dietary diversity. Rome: Food and Agriculture Organization, 2011. $53 \mathrm{p}$.

28. Ferro-Luzzi A, James WP. Adult malnutrition: simple assessment techniques for use in emergencies. $\mathrm{Br} J$ Nutr 1996;75:3-10.

29. Brown KH, Rivera JA, Bhutta Z, Gibson RS, King JC, Lönnerdal B et al.; International Zinc Nutrition Consultative Group (IZiNCG). International Zinc Nutrition Consultative Group (IZiNCG) technical document \#1. Assessment of the risk of zinc deficiency in populations and options for its control. Food Nutr Bull 2004;25(Suppl 2):S99-203. 
30. Central Statistical Agency. Ethiopia demographic and health survey 2005. Addis Ababa: Central Statistical Agency, 2006. 410 p.

31. Friis H, Gomo E, Koestel P, Ndhlovu P, Nyazema N, Krarup $\mathrm{H}$ et al. HIV and other predictors of serum betacarotene and retinol in pregnancy: a cross-sectional study in Zimbabwe. Am J Clin Nutr 2001;73:1058-65.

32. Biswas AB, Mitra NK, Chakraborty I, Basu S, Kumar S. Evaluation of vitamin A status during pregnancy. J Indian Med Assoc 2000;98:525-9.

33. Meram I, Bozkurt AI, Kilincer S, Ozcirpici B, Ozgur S. Vitamin A and beta-carotene levels during pregnancy in Gaziantep, Turkey. Acta Medica (Hradec Kralove) 2004;47:189-93.

34. Dijkhuizen MA, Wieringa FT, West CE. Pregnancy affects plasma concentration of retinol and acute phase proteins. In: Clewes C, Thurnham D, Dijkhuizen $\mathrm{M}$, editors. Vitamin A and the common agenda for micronutrients. Report of the XXII International Vitamin A Consultative Group Meeting, Lima, Peru, 15-17 November 2004. Washington, DC: International Vitamin A Consultative Group, 2005. 102 p.

35. Schweigert FJ. Inflammation-induced changes in the nutritional biomarkers serum retinol and carotenoids. Curr Opin Clin Nutr Metab Care 2001;4:477-81.

36. Thurnham DI, McCabe GP, Northrop-Clewes CA, Nestel P. Effects of subclinical infection on plasma retinol concentrations and assessment of prevalence of vitamin A deficiency: meta-analysis. Lancet 2003;362:2052-8.

37. Stephensen CB, Gildengorin G. Serum retinol, the acute phase response, and the apparent misclassification of vitamin A status in the third National Health and Nutrition Examination Survey. Am J Clin Nutr 2000;72:1170-8.

38. Katz J, Tielsch JM, Thulasiraj RD, Coles C, Sheeladevi $\mathrm{S}$, Yanik EL et al. Risk factors for maternal night blindness in rural South India. Ophthalmic Epidemiol 2009;16:193-7.

39. Katz J, Khatry SK, West KP, Humphrey JH, LeClerq $\mathrm{SC}$, Kimbrough E et al. Night blindness is prevalent during pregnancy and lactation in rural Nepal. J Nutr 1995;125:2122-7.

40. Semba RD, de Pee S, Panagides D, Poly O, Bloem MW. Risk factors for nightblindness among women of childbearing age in Cambodia. Eur J Clin Nutr 2003;57:1627-32.

41. Winkvist A, Rasmussen KM, Habicht JP. A new definition of maternal depletion syndrome. Am J Public Health 1992;82:691-4.

42. Christian P, West KP, Jr. Interactions between zinc and vitamin A: an update. Am J Clin Nutr 1998;68(Suppl 2):435S-41S.

43. Baly DL, Golub MS, Gershwin ME, Hurley LS. Studies of marginal zinc deprivation in rhesus monkeys. III. Effects on vitamin A metabolism. Am J Clin Nutr 1984;40:199-207.

44. Christian P, Khatry SK, Yamini S, Stallings R, LeClerq SC, Shrestha SR et al. Zinc supplementation might potentiate the effect of vitamin A in restoring night vision in pregnant Nepalese women. Am J Clin Nutr 2001;73:1045-51. 